\title{
Pussy power not pity porn: embodied protest in the \#FacesOfProstitution Twitter network
}

\section{Introduction}

To mark the 25th anniversary of the release of Hollywood blockbuster Pretty Woman, religious group Exodus Cry published a blog post that was later shared on the Australian based feminist blog site Mamma Mia criticizing the film for its glorification of sex work. In the film, Vivien (Julia Roberts), a Beverly Hills street hooker is saved from her life of prostitution when she falls in love with her client Edward (Richard Gere), a wealthy businessman. The original blog post 'Think the fantasy of prostitution in Pretty Woman is harmless? Think again' included the image of a bruised, beaten and semi-naked woman beside a film still of Vivien's laughing face in an apparent equation of sex trafficking with commercial sex. In response to the blog post, a young Sydney sex worker named Tilly Lawless posted a selfie on Instagram and later Twitter with the caption, "There is no singular story or person to represent the varied \& complex experiences of all sex workers, but here is one face of prostitution amongst a myriad \#FacesOfProstitution' (reproduced with permission in Figure 1). Lawless' gesture resonated with sex workers the world over who responded in their hundreds by posting selfies on Twitter using \#FacesOfProstitution. Though the campaign received scant local media coverage in Lawless' home state of New South Wales, Australia where sex workers operate in a decriminalized legal framework, there was widespread media attention in the UK and Europe across radio, print and online. In those media interviews, Tilly Lawless, Lucie Bee and other Australian sex workers emphasized the importance of bodies in their political protests. For Lawless, '[Sex workers] are very rarely humanised as individuals, so often our bodies are spoken about but putting our faces on social media is such a powerful thing' (Bloom, 2015). Bee echoed these sentiments in her interview with news.com.au, 'People don't understand how you could possibly go into the industry by choice. They say, how could you do this? How could you interact on this level with people you don't know? It implies we don't have any agency over our minds and bodies' (Sullivan, 2015). By posting selfies on social media the \#FacesOfProstitution tweeters were not only using their bodies as an instrument of political protest but articulating new modes of political organizing, agency and information dissemination within a networked online community. The visibility of their faces and bodies online was aimed at generating greater social acceptance for sex workers internationally and petitioning for their legal protection through decriminalisation. As a case study, the self-identificatory practices tweeters used contribute to current discussions about selfies in the context of 'individualized collective politics' (Bennett, 2012), embodied forms of activism in online spaces (van der Nagel, 2013; Tiidenberg, 2014) and biodigital politics as an emerging concern of feminist social movement theory (Fotopoulou, 2017).

Taking a two-pronged approach this study will consist of a qualitative content analysis of tweets using the hashtag \#FacesOfProstitution complemented by an analysis of data derived from Twitonomy, a commercial analysis tool, to address the following questions: what is the role of the body in an online protest network 
of sex workers? What are the opportunities for transformation and new forms of gendered embodiment that technologies and virtual communities of cyberspace offer marginalised women, in particular those operating in a perceivably discreditable profession? These questions will be answered using an interdisciplinary framework that draws upon feminist-materialist literature, feminist social movement theory and research on sex work activism. In particular, the current study contributes to the minimal literature on digital activism in sex work communities (Jones, 2015; Sanders, Scoular, Campbell, Pitcher and Cunningham, 2018), and has implications for the way we perceive marginalized communities in online spaces and their embodied practices that both legitimate and authenticate online forms of resistance.

\section{Selfies and DIY politics}

The term selfie describes what is now a ubiquitous social practice variously referred to as 'self-shooting' (Tiidenberg, 2014), 'selfie portraits' (Mazza, Da Silva and Le Callet, 2014) and 'self-generated digital photographic portraiture' (Senft and Baym 2015,1588). Research on selfies is prodigious with previous studies examining selfie-taking by teenagers (Dobson, 2015; Marwick, 2015), the use of selfies among elite user groups (eg. politicians, see Abidin, 2017; celebrities see Jerslev and Mortensen, 2016), life cycle selfies (eg. selfies at funerals, see Gibbs, Meese, Arnold, Nansen and Carter, 2015; Leaver and Highfield, 2015; and selfietaking while sick or injured, see Tembeck, 2016), dating apps and the reshaping of perceptions of intimacy (David and Cambre, 2016) and the performance of citizenship through selfie-taking (Kuntsman, 2017). Fewer contributions analyze the embodied dimension of selfie culture or gendered selfie production practices. Bonilla and Rosa (2015) explore the social media campaign following the 2014 death in Ferguson, Missouri of African American teenager Michael Brown in the context of US racial politics. In their ethnographic analysis of tweets using \#Ferguson, the researchers found that through self-recorded images tweeters called attention to racially motivated policing systems, the 'vulnerability of black bodies' and contested official, victim-blaming narratives (2015: 8). In these selfpresentational strategies tweeters reveal the potential for challenging mediated representations of a marginalized group and assert 'the fundamental value and the particularity of their embodiment both on- and off-line' (2015: 9). Though their focus is on racialized rather than gendered bodies, the study is useful for considering the way bodies are rematerialized in online spaces in opposition to dominant media narratives and prevailing stereotypes of a marginalized group.

Applying a gendered lens to their discussion of embodied engagement in selfimaging practices, Tiidenberg and Cruz (2015) analysed 'sexy selfies' on the NSFW (Not Safe For Work) Tumblr blogs. Drawing on Tiidenberg's 2014 study, they found that selfies facilitate women's experience of their bodies outside of a limiting, normative discourse and foster 'new ways of looking', body-positivity, feminist and queer-friendly practices as well as inter-communal engagement in social networks (Tiidenberg and Cruz, 2015: 84). Tiidenberg and Cruz's argument about the corporeal-based politics of selfie-taking informs this analysis of \#FacesOfProstitution tweeters and, in particular, their fostering of new ways of seeing, knowing and experiencing the body (Tiidenberg and Cruz, 2015). 
The selfie has also been viewed as an 'object of politicizing discourse' (Senft and Baym, 2015: 1589), an exercise in 'political work' (Kuntsman, 2017) and can be understood as part of 'a wider, contemporary phenomenon of 'self-actualizing, digitally mediated DIY politics' (Bennett, 2012: 30, see also Sheehan, 2015). For W. Lance Bennett, changing patterns of popular participation now characterise the political landscape. Rather than social movements defined by 1960 s-era conventional group identities (eg. the marginalised, women, immigrants), individuals are now mobilised around 'personal lifestyle values' that tap into broader themes about international human rights, inequality and environmental preservation (among others) and use digital media technologies to facilitate content sharing and coordinate their actions in online networks (Bennett, 2012: 37). That digitally enabled coherence of individuals in support of a humanitarian cause has relevance for the present study of tweeters who mobilized under \#FacesOfProstitution to petition for human rights and labour rights for sex workers. Thus, the term 'network' used here derives from an understanding of the emergence of crowd-led and technology-enabled movements that are characterized by 'diversity and inclusiveness' and are part of a larger shift towards 'personalised politics' (Bennett, 2012: 21-22). The diverse and inclusive ethos fostered in the \#FacesOfProstitution network was based on a corporeal politics and, for this reason, the following section teases out debates about embodiment in feminist scholarship and cyberfeminist research.

\section{Corporeal politics}

Historical and gender inflected views about the emancipatory potential of cyberspace as a disembodied and anonymised realm (Heim, 1992; Turkle, 1995; Shade, 1996; Rheingold, 1993) were popular in cyberspace research in the 1990s. Proponents emphasised the emancipatory potential of online spaces in which the mind could be liberated from the encumbrances of the physical body (Moravec, 1988; Lanier and Biocca, 1992; Kurzweil, 1999) in an extension of Enlightenment views associating 'masculine' rationality and logic with the mind and 'feminine' passion and unreason with the body (Sundén, 2003: 5). Anne Balsamo calls this way of thinking the 'logic of binary gender-identity' in what has become the 'organisational framework' of contemporary discourses about information technology (Balsamo, 1996: 9-10). More specifically, the mind-body dichotomy undergirds conceptions of a post-corporeal utopian cyberspace wherein masculinity is abstracted and normativised and femininity is contingent and othered (Sundén, 2003: 5, see also gender neutrality in Klein in Hawthorne and Klein, 1999: 206). Though these views are somewhat outdated given the emergence of image sharing platforms such as Instagram and Snapchat and the expansion of the digital image in selfie culture, the historical legacy of subordination of the female body has political implications according to a number of feminist researchers because the body is a key site of women's political subjectivity (Grosz, 1994; Balsamo, 1996; Hayles, 1999; Braidotti, 2002; Travers, 2003). Barbara Sutton argues that activist bodies in their materiality, emotionality and symbolic representation are integral to collectivization (Sutton, 2010: 189). Similarly, Wendy Parkins points to an indissoluble connection between the body and political resistance since 'we cannot think of political 
agency in abstraction from embodiment' (Parkins, 2000: 60). Positioned at the centre of a social transformation catalysed by communications technologies (Balsamo, 1996: 39), the body is the driving force of women's protest movements (Parkins, 2000; Sutton, 2010).

For cyberfeminists, though there is collective concern about the relationship between gender and digital culture (Flanagan and Booth, 2002: 11) and agreement on the scope of cyberfeminist practices (Flanagan and Booth, 2002: 12; Chatterjee, 2002: 199; Fernandez, Wilding, and Wright, 2003: 9-13; Daniels, 2009: 102-3), there is no unified feminist political objective (Chatterjee, 2002; Daniels, 2009). This lack of consensus is evident in what have been categorised as 'old' and 'new' cyberfeminisms: the former a utopian vision of women's material transcendence in the digital realm and the latter an embodied politics that emphasizes women's differing self-identification practices and access to information technologies (Daniels, 2009: 187; Klein in Hawthorne and Klein, 1999: 193; see also Fernandez, Wilding and Wright, 2003). Among the 'old' guard, for instance, Hansen (2006) and Nouraie-Simone (2005) argue that the Internet is an escape from embodiment whereas for Haraway (1990), Grosz (1994) and Balsamo (1996) the female body, represented in the metaphor of the cyborg and at once materially and discursively produced, is a site of political resistance (Balsamo, 1996: 39). It is through an embodied lens that the following analysis of a sex work online community is considered; an analysis faithful to Balsamo's argument that '...the female body is the site at which we can witness the struggle between systems of social order. In the process, new forms of gendered embodiment emerge which on the one hand may display inherited signs of traditional dichotomous gender identity, but which also reinvent gender identity in totally new ways' (Balsamo, 1996: 39). Tracing the emergence of 'new forms of gendered embodiment' in the Twitter campaign \#FacesOfProstitution will show how communications technologies are not only 'recrafting our bodies' in new domains (Haraway, 1990: 82) but providing new platforms for collectivizing and articulating women's political projects in an embodied fashion.

Though the body, gender and sexuality are key concerns in feminist scholarship, within the literature on networked social movements (Bennett and Segerberg, 2013; Castells, 2012; Earl and Kimport, 2011; Faris, 2013; Juris, 2008; Rossiter, 2006), these sites of contestation and political struggle are noticeably absent 'despite their centrality' (Fotopoulou, 2017: 7). In her feminist-materialist contribution, Aristea Fotopoulou offers the concept of 'biodigital vulnerability' as a crucial terminological link between activism, digital media and embodiment (2017: 16). Biodigital vulnerability outlines the way in which digital networks can exist as spaces of both precarity and resistance for those who contribute to them. The contradiction she highlights in online visibility is also true of the \#FacesOfProstitution contributors whose tweets demonstrate the complexity of being female and public online, paradoxically both vulnerable and empowered. In her analysis of feminist digital activism Baer situates this contradiction in neoliberal discourse that 'emphasizes the body as a site of empowerment' and yet subject to 'constant surveillance, monitoring and discipline' (Baer, 2016: 23). Examining the different modalities used by \#FacesOfProstitution tweeters will highlight the tension between empowerment and control articulated in their 
body-based politics. What follows is an historical analysis of the differing modalities employed by sex work activists to situate the present case study.

\section{Sex work activism}

Research on the politics of sex worker activism is multifocal with emphasis on the collectivization and unionization of sex workers campaigning for sex worker rights and policy developments (Sanders, O'Neill and Pitcher, 2009), the mobility of sex workers and international alliances (Garofalo in Ditmore, Levy and Willman, 2013), and the use of activist media practices challenging mainstream depictions of sex work (Cheng, 2013). Most of the activist literature centres on traditional forms of protest such as street marches, sit-ins and petitions. Yet, as with other sex markets (eg. hook up apps and pornographic websites) that have been mainstreamed and professionalized as a consequence of digital technologies, the Internet has radically transformed the meaning, experience and provision of sex work services (Bernstein, 2007; Jones, 2015). For sexual minority groups and marginalised sex-specific communities online environments provide interactive space (Ashford, 2009), extend awareness of services, domains of access and information dissemination within the community and instill 'camaraderie' among sex workers whose communal bonds are forged in the context of public and sometimes self-perceptions about their 'discreditable' profession (Bernstein, 2007: 479, see also Lane, 2000; Sharpe and Earle 2003).

Though there is active research on the varying dimensions and expressions of sex work activism (Laing, Pilcher and Smith, 2015; Ditmore, Levy and Willman, 2013), research on digital forms of protest within sex work communities is largely lacking (Jones, 2015; Sanders, Scoular, Campbell, Pitcher and Cunningham, 2018). Among the notable exceptions is Valerie Feldman (2014) whose research considers the US-based sex worker activist blog Bound, Not Gagged (BnG) as a tool for the collective organization and political mobilization of sex workers. Written by and for sex workers, BnG was the first multi-authored blog devoted to sex work activism and later became a 'mouthpiece for [the sex worker] movement' in the US (Feldman in Showden and Majic, 2014: 244). Angela Jones (2015: 563) makes passing reference to the political benefits of online activism for sex workers though without an exemplary case study. More recently, Sanders, Scoular, Campbell, Pitcher and Cunningham (2018), in their research of UK sex workers, found that 'online spaces have provided a platform for campaigns for sex worker rights and for challenging UK government policies, media/cultural misrepresentations and stereotypes of sex workers' (Sanders et al., 2018: 45). Their conclusion about the potential of online platforms to articulate the political objectives of sex workers has resonances for this study since contributors to the \#FacesOfProstitution network petitioned for the international rights of sex workers, confronted whore/victim stereotypes and united in solidarity against network infiltrations from anti-sex work activists.

\section{Method}

After posting her captioned selfie on Instagram and again on the Scarlet 
Alliance's Facebook page, Lawless was persuaded to reproduce the image, text and hashtag on Twitter. Soon Twitter became the principal networking platform for sex workers posting the hashtag in a moment the BBC described as: 'And then it began: a mass of hundreds of mostly Australian and mostly female sex workers posted images showing their faces to the world, many coming out publicly as sex workers on social media for the very first time' (Newby, 2015). It is for this reason that the present study focuses on user generated content on Twitter in particular.

Established in 2006, Twitter is a microblogging site used to post messages or 'tweets' of initially 140-characters (increased to 280 characters in November 2017) at an average rate of 500 million per day (Internet Live Stats). Users build a network of followers and 'followees' and information is grouped according to 'a system of "channel tags" using the pound or hash (\#) symbol' that organize conversation around a particular topic or event (Bruns and Burgess, 2011: 2). As Bruns and Burgess argue, by hashtagging tweeters interpellate an 'imagined community of users' who are often comprised of those participating in the topic ('the hashtag community') and their own followers ('follower network') thereby bridging dual layered networks (Bruns and Burgess, 2011: 4). As a connective, aggregation mechanism the hashtag makes content discoverable on the platform and on popular search engines such as Google. According to Twitonomy, a commercial, third party Twitter analytics program, the potential reach of the hashtag, calculated on 7 September 2015, was estimated at 103,566 accounts internationally. This statistic is illustrated best in the program's geolocating map tool which reveals that in the six months after the original post contributors tweeted from 39 countries around the world. Twitonomy also gives us a snapshot of the popularity of Tilly Lawless' original post that received 103 'retweets' or re-postings and 193 likes or 'favourites' on her Twitter profile. While the originator of the hashtag, Lawless was by no means the most prolific tweeter. According to Twitonomy's categories of influence the 'most influential users' were Mistress Picasso and Scarlettxxx with over 24,000 followers each. However, the 'most engaging user' based on number of re-tweets was the IAASWA organization - the International Association of Allies of Sex Worker Activist - an organization which supports the decriminalization of sex work. Through user data snapshots and geolocating tools Twitonomy provides insight into the 'different kinds of content' (Neuendorf, 2017: 221) offered by this microblogging platform and, in particular, an understanding of both the global reach and interpersonal functioning of the \#FacesOfProstitution network. In this instance, the variety and spread of contributors suggests the hashtag was not driven by any one Tweeter or activist but by a variety in a diffuse network.

Aside from Twitonomy's quantitative data snapshot, this study uses qualitative content analysis to provide a more nuanced picture of individual tweeters whose selfies and accompanying explanatory tweets gave the community its corporeal identity, 'camaraderie' (Bernstein, 2007: 479) and sense of purpose. According to Holsti, content analysis is defined as "any technique for making inferences by objectively and systematically identifying specified characteristics of messages" (Holsti, 1969: 14). Adopting an inferential and qualitative reading of \#FacesOfProstitution tweets rather than the more explicit, quantitative counting 
procedure (see Riffe, Lacy and Fico, 2005 on the difference between manifest and latent content), this study included latent textual and visual content (the latter exemplified in selfies and memes), that not only characterized the \#FacesOfProstitution network and its contributors but was responsible for the hashtag's virality. Content was hand-coded using an historical timeline of tweets across a seven-month period from 28 March 2015, when Tilly Lawless' hashtag first appeared, to 20 October 2015 when she posted one of her last selfies with the hashtag (atop a cruise liner in front of the Sydney Harbour Bridge with the tweet, 'one of my better days at work'). More than 200 tweets including selfies and memes were selected in that period with particular attention given to retweeted tweets because of their prominence in the network and the apparent communal identification with the content. Selfies with captions or textual tweets were analysed together. In all, 189 tweets were hand coded after the material was filtered for relevance and content similarities.

\section{'Show your face to our hashtag'}

Within two days of its inception the hashtag \#FacesOfProstitution was trending on Twitter and sex workers around the world self- mobilized in response to the online campaign. Many contributors reached out for a constituency by posting, sharing and re-tweeting messages in the hours after Tilly Lawless posted on Twitter. MadamMinxx appealed to the persecuted in her tweet, 'Are you a sex worker sick of being told how oppressed and victimised you are? If you can show your face to our hashtag' while others issued the rallying cry, 'Calling all sex workers who don't mind showing faces online: tweet a pic on \#FacesOfProstitution to show prohis we aren't miserable victims'. For some it was the first time they had taken a selfie or 'come out' online as a sex worker as Maggie tweeted, 'here's my $1^{\text {st }}$ selfie EVER' (28 March 2015, reproduced with permission in Figure 2), and others such as MadamMinxx, presumably more familiar with the codes of self-presentation, tweeted 13 times on the first day (28 March 2015). Digital access appeared less of a barrier for contributors who posted 'on request from a friend without Twitter' (MadamMinxx 29 March 2015) or upskilled by contributing to the network and following its norms in comments such as 'Unexpected perk: \#FacesOfProstitution has totally learned [sic] me how to drive Twitter' (Audrey Gonzalez, 3 April 2015). Moreover, geography proved little impediment to contributors. Some posted selfies depicting their quotidian lives, friends and family and others tweeted selfies from abroad. Ms Isabella Cox in a makeup-less selfie with headphones, tweeted 'Sitting beside you at a coffee shop, I doubt you'd take me for a harlot' (29 March 2015). Emily uploaded a series of photographs with her family declaring, 'I'm a prostitute who loves my parents, and they LOVE me! We have fun every chance we get' (31 March 2015). While Sofia See uploaded a travel selfie in front of the Penny Lane sign in Liverpool England, made famous by The Beatles' song, along with the caption 'untouched photo' (29 March 2015). Aside from their global provenance, these selfies capture the raw ('untouched' by photographic filters), and human ('we have fun' and 'sitting beside you at a coffee shop') face of sex work. In these tweets, contributors were actively 'recrafting [their] bodies' in new domains (Haraway, 1990), celebrating and accepting their 'variations of corporeality' (Tiidenberg and Cruz, 2015) and opposing dominant media narratives of sex 
workers as either bruised and battered sex trafficking victims or glossy heroines in celluloid fairytales such as Pretty Woman.

True to Tilly Lawless' originating post about the 'myriad' faces of prostitution, there were no typical self-presentations or bodily norms established in the network. Some posted 'Seriously average' selfies 'in reading glasses and without makeup' (Harper Simmons 3 April 2015), while others were seductively postured in bed 'getting ready for work' (Avery 3 April 2015), lying in a bubble bath (MadamMinxx 28 March 2015), or in dominatrix-inspired lingerie with black leather bra and red lipstick (Mistress Lily, 29 March 2015). For materialist feminists, female subjectivity originates in the corporeal and, far from being fixed and immutable, articulates multiplicity, complexity and, often, contradictory realms of experience (Braidotti, 1989, 1993; Grosz, 1994). That diversity was reflected in the range of contributors to the network whose social markers such as age, ethnicity, gender and sexuality appeared no barrier to entry. Leah Martin tweeted along with her selfie in black feather hat, 'Me, 57 (the hat is 80 years older)' (24 April 2015) and similarly Madeline tweeted, 'I'm showin that ANYONE regardless of age CAN/WILL be a prostitute for their own reasons' (6 May 2015). The ethnicity and sexual identity of sex workers in the network was proudly declared in tweets such as "This is what a Swedish sex worker looks like' (Inga, April 2015) and 'I'm an independent pre-op transgender \#sexworker in Korea' (SerenityX, 31 March 2015) or, as in the case of US-based sex worker Alexis Carter, not mentioned at all in favour of other selfidentifying descriptors such as 'non-smoker, non-drinker, vegetarian' (1 April 2015). The acceptance of all sex workers irrespective of age, gender, ethnicity and sexual identity follows Tiidenberg and Cruz's (2015) findings about the inter-communal, body-positive, feminist and queer-friendly practices cultivated in the NSFW network (Tiidenberg and Cruz, 2015: 84).

\section{'Show feet and support \#FacesOfProstitution'}

A number of tweeters took selfies of intimate body parts to signify their anger over the original article published on Mamamia and the prevailing rescue narrative in media coverage of sex work. Aubree Peterson posted a monochrome, close-up photograph of her middle finger raised in protest (29 March 2015), not unlike Peyton Longmann's selfie of her elevated middle finger and miniskirted torso, fishnetted legs and boots with the tweet, 'I love my kids, I donate to many charities for both human and animal welfare' (29 March 2015). Rather than her middle finger, Delilah Harris posted a close-up photograph of her substantial cleavage in black negligee with the tweet, 'Just hanging out. Love boobs. Loved sex work. We're awesome' (22 April 2015). For security and to safeguard what was likely to be their 'plausible deniability' in the case of identification (Tiidenberg, 2013) some tweeters posted selfies in soft focus (Harlot Henderson, 29 March 2015; Autumn Davis 3 April 2015) used props and other devices such as a handbag (Khloe Allen, 29 March 2015), a wad of Australian bank notes (Mia, 5 April 2015), sunglasses (Piper Dream, 1 April 2015) or lowlight conditions at night to conceal their faces (MadamMinxx 29 March 2015). Some users posted images of their personal effects thereby registering bodily 'traces' as a form of protest. Violet Macc posted a photograph 
of one of her sneakers along with the caption, 'Show feet and support \#FacesOfProstitution. Don't judge a person til you have walked in their shoes. My feet + normal. So am I. \#feetofprostitution' (21 April 2015, reproduced with permission in Figure 3). Attempts by tweeters to use signifying body parts or conceal their identities in selfies were no less significant as 'object[s] of politicizing discourse' (Senft and Baym, 2015: 1589) than other digital portraits posted by tweeters in the network; in fact, in their 'biodigital vulnerability' (Fotopoulou, 2017) such selfies point to the precarity and risk of embodied forms of activism and the complicated identity work that occurs in online spaces.

Aside from selfies, some sex workers asserted their bodily autonomy in tweets such as 'Only I negotiate the terms under which I have sex. My body - My right' (Elyssia Bakerman, 5 April 2015). In a post that was re-tweeted several times in the network, Kimberly Jones explained to tweeter @DannyBoy that the campaign was intended to entify and 'make real' sex worker identity, '@DannyBoy dude, do you have any idea what we're doing with the \#FacesOfProstitution hashtag? It's personalizing us. Humanising. We're people' (9 April 2015). Similarly, Ellie May Archer devoted five consecutive tweets to fleshing out her subjectivity in comments such as 'I'm addicted to nutella', 'I've delivered pizza', 'My uncle died a few months ago', 'I'm a loving, breathing, intellectual, emotional, tired of work drama, want more time with my fam, real, human person' and 'WE ARE PEOPLE' (8 April 2015). In the absence of a selfie, these and other textual tweets evoking the physical body strengthen 'the indissoluble connection' between political agency and embodiment (Parkins, 2000: 60).

\section{'Pimpmutts', humour and resilience}

To challenge mainstream media depictions of sex work and victimhood stereotypes many tweeters used humour. Rylee in Griffith tweeted, 'OMG! They make me prostitute AND a volunteer for aged care! This madness has to stop! SAVE ME! \#FacesOfProstitution' (30 March 2015). MadamMinxx posted a bubble bath selfie and accompanying tweet in reference to the Star Wars film franchise, 'The bubbles of oppression are strong with this one. How will I ever cope without rescue?' (MadamMinxx, 28 March 2015), while Clara Colins' tweet recalled another popular Hollywood film, 'Dead Poets Society inspired me to be a (broke) academic. A great wage inspired me to be a hooker. \#FacesOfProstitution' (29 March 2015). Some posted memes such as 'Sex Workers Unite!' (Valentina Robinson, 31 March 2015) or 'Keep Calm and Love your Sex Worker' (Luna Lewis 31 March 2015), while others posted selfies with their pets, 'I sometimes take my dog to work. Oh no! Even my children are on the "game"' (Audrey Gonzalez, 29 March 2015) and MadamMinxx whose nose-tonose selfie with her white Maltese terrier was captioned, 'Help help. I'm being oppressed! This little pimpmutt will beat me if I don't work' (28 March 2015). These humourous tweets are an example of the contestation of dominant media and cultural representations within and facilitated by online spaces (Sanders et al., 2018). Moreover, in their array of selfies, contributors not only used humour 'as a political tool for building resilience' in the network (Fotopoulou, 2017: 16), but also exercised new and embodied activist practices. 


\section{'Go floosies!'}

A number of sex workers used the hashtag to offer messages of solidarity and support to others in the industry. Sara Swan tweeted, 'Proud of my Australian sisters. You rock girls!!' (30 March 2015), while Emily, in a selfie with her reading glasses, tweeted, 'I'm so proud that this movement has gained such positive momentum! 10 years as a sex worker!' (30 March 2015). The communal pride among sex workers was also evident in London Lees' tweet 'Go floosies!' (3 April 2015), SexWork 101's 'Congrats to all involved' (7 April 2015), Scarlet Alliance's 'The \#FacesOfProstitution has achieved so much in 2 weeks!' (11 April 2015) and The Treasure Trove's ‘\#FacesOfProstitution takes off globally’ 7 April 2015). Popular among members of the network was the use of associated hashtags such as '\#rights not rescue', '\#not your rescue project', '\# being a sex worker taught me' and let's talk '\#sex work'. These hashtags not only extended the network's reach to an 'imagined community of users' (Bruns and Burgess, 2011: 4) but exemplified the 'camaraderie' among tweeters in the network (Bernstein, 2007: 479).

Several sex workers used the campaign to push for the decriminalization of sex work across Australia and internationally (New South Wales in Australia, New Zealand, Switzerland and Uruguay are among the few jurisdictions operating in a decriminalized, liberal framework), for the elimination of social stigma and discrimination, and for legislative protection in the workplace. For Adalyn Annesley, '\#Decriminalising \#sexwork aids the safety of all women by not creating a shunned underclass that predators can target' (Adalyn Annesley 23 April 2015) while Lydia Ash underscored the need for equality, 'Sex workers are people. Whatever our story, we need labour rights' (14 April 2015). Tweeter Sex Work 101 explained the nomenclature surrounding sex work, "The hashtag \#FacesOfProstitution uses "Prostitute" to reply \& reach out to those who consider us victims. Our preferred term is "sexworker"' (30 March 2015). These examples are evidence of the use of the network as a channel to inform and educate a wider audience, contributing to a general push for the legislative protection of sex workers the world over (Chapkis, 1997; Fawkes, 2005; Thukral et al., 2005). Though the hashtag provided a platform for sex workers and their advocates to educate and inform the public, tweets from outside the community point to the 'loosely affiliated' structure of the network, its porous boundaries and, as the following examples show, its 'vulnerability to invasion' as is characteristic of online networks (Rossiter, 2006).

\section{Educating 'prohis' and 'haters'}

Within two weeks of the hashtag's inception anti-sex work organisations such as Sex Industry Kills, Sextrade101 and sex work abolitionists such as Sarah McKenzie and Sebastian Moreno infiltrated the network. Sex workers referred to these organisations and individuals as 'prohis' (prohibitionists), 'antis', 'abolitionists' and 'haters'. A prolific and what Twitonomy referred to as 'the most engaging user' of the hashtag was Sex Industry Kills, an organization promoting the abolition of sex work. Sex Industry Kills used anonymous accounts to troll the site with anti-sex work messages and photographs of 
murdered victims of sex buyers such as 'Christine Paddock was killed in street prostitution' (7 May 2015). Destiny X tweeted that such posts were an attempt to undermine sex worker subjectivity: 'Non \#sexworkers using images of dead \#sexworkers in a campaign to undermine live \#sexworkers is beyond disgusting' (15 April 2015). While Emery Eve thought them distasteful, 'We didn't enter for the "right" reasons so we'll just post pictures of dead sex workers. Sure to help' (12 April 2015), Tilly Lawless commented on their unwelcome invasion of the site, 'Antis aren't witty enough to think of their own hashtag or respectful enough to let sex workers speak for themselves' (21 April 2015). In response, members of the network such as Lee demanded 'antis' uncloak their anonymity, '...come on you self-righteous antis, show your faces' (Lee ,13 April 2015), others focused on 'spreading love, not hate' (Piper Dream, 1 April 2015), some ignored critics and instead tweeted their admiration for the sex work community, 'Not int' in engaging w/ anti \#hatespeech tonight. It's more impt to keep \#sexworker pride going' (Luna Lewis, 31 March 2015), while others directly addressed 'prohis' and attributed the amplification of their voices to technology, '@Sarah McKenzie you and your kind have been silencing us forever. Because of social media we finally have a voice' (Alexis Carter, 22 April 2015). By May 2015, however, Alexis Carter tweeted the 'antis' campaign was exhausted and opined their next strategy, 'Well, it seems the antis have given up on \#FacesOfProstitution, maybe we can find another hashtag to spread our antioppression message?' (4 May 2015). Despite the climate of risk, contributors to the hashtag publicly exposed their sex worker identities in defiance of the prevailing politics of anonymity surrounding sex work. Their embodied media practices reveal the complexities of being female and public online and the conditions of empowerment and vulnerability that characterise the biopolitics of digital networks (Fotopoulou, 2017).

\section{Conclusion}

Using the case study \#FacesOfProstitution this paper offers an important intervention in an otherwise limited debate about digitally enabled sex work activism. The argument advanced here is that the \#FacesOfProstitution campaign is an example of activism of a mediated/networked kind and mobile relations forged as a result should be seen as important forms of resistance to mainstream views and assumptions about sex work and sex worker identities. Feminist materialism, feminist social movement theory and sex work activism provide an interdisciplinary framework for understanding in general, the intersections of mind, body and technology in networked environments, and in particular, the array of digital communication practices among sex workers. Whether posting a selfie, stand-in signifier, blurred image, prop or textual description of their bodies, tweeters affirmed the corporeality of their protests and the 'myriad faces of prostitution' captured in Lucia Hoffmann's tweet, 'When will people accept that "faces" is plural and that there are multiple experiences, lives, backgrounds \&motives? [sic]' (30 April 2015).

In the context of what Bennett $(2012,37)$ describes as an historical shift towards 'personalised forms of activism' and mobilised around 'personal lifestyle values' in defence of human rights and equality, tweeters in the network used digital 
media technologies to share content, offer support, publicise and coordinate their actions. Importantly, selfies provided \#FacesOfProstitution tweeters the platform to confront whore/victim stereotypes, consistent with the findings of Sanders et al.'s (2018) study of UK sex worker advocacy online. Additionally, the \#FacesOfProstitution network is a ready example of online spaces fostering 'camaraderie' (Bernstein, 2007: 479) among marginalized groups and providing a space for the collective organization and political mobilization of sex workers (Feldman, 2014), with these findings contributing to the limited scholarly discussion about digital forms of sex work activism.

While the public posting of sex worker selfies exposed contributors to 'prohis', 'antis', trolls and other detractors who infiltrated the network, the diversity of their digital self-portraiture revealed gendered sex worker bodies experiencing new forms of collectivity and empowerment (Tiidenberg, 2014) in a climate of risk and precarity explored here through the concept of 'biodigital vulnerability' (Fotopoulou, 2017). What is particularly striking about the \#FacesOfProstitution tweeters is their use of selfies to assert the professional and personal value of sex workers ('proud to be a sex worker') and the particularity of their embodiment ('sex workers have many faces') to contest normative views and assumptions about sex work and sex worker identities in a form of 'individualized collective politics' (Bennett, 2012).

In all, the FacesOfProstitution campaign should be seen as an important online insurrection that was an embodied, public and political performance of sex worker identities fostering 'new ways of looking', knowing and experiencing the body (Tiidenberg and Cruz, 2015: 84) and countering more dominant, mainstream media representations. As KittyWade underlined in her tweet accompanied by the photograph of a hissing cat: 'Here is a photo of how angry my pussy gets when people tell me what I can and can't do with it' (March 2015). Rather than rely on the pity porn circulated in victim narratives about sex work, a more productive and empowering conversation would involve sex workers themselves, articulating new and embodied activist practices as exemplified in \#FacesOfProstitution.

\section{AUTHOR STATEMENT}

The author has chosen to anonymize most of the Tweeters quoted in this article, despite their online visibility and public utterances in the \#FacesOfProstitution network, because of the differing legal and regulatory frameworks in which sex workers are operating around the world and the need for greater protection of such marginalized communities.

\section{REFERENCES}

Abidin C (2017) Vote for My Selfie: Politician Selfies as Charismatic Engagement. In: Kuntsman A (ed) Selfie Citizenship. Manchester, UK: Palgrave Macmillan, pp.75-87. 
Ashford C (2009) Queer theory, cyber-ethnographies and researching online sex environments'. Information Communications Technology Law 18(3): 297-314.

Newby G (2015) Faces of Prostitution in Australia. BBC News Trending, 3 April. Available at: http://www.bbc.com/news/blogs-trending-32165949

(accessed 28 December 2017)

Baer H (2016) Redoing feminism, digital activism, body politics and neoliberalism. Feminist Media Studies 16(1): 17-34.

Balsamo A (1996) Technologies of the Gendered Body: Reading Cyborg Women, Durham and London: Duke University Press.

Bennett WL (2012) The Personalization of Politics: Political Identity, Social Media, and Changing Patterns of Participation, The Annals of the American Academy of Political and Social Science, 644: 20-39.

Bennett WL and Segerberg A (2013) The Logic of Connective Action: Digital Media and the Personalization of Contentious Politics. Cambridge: Cambridge University Press.

Bernstein E (2007) Sex work for the Middle Classes, Sexualities 10(4): 473-488. Bloom D (2015) Faces of Prostitution: sex workers fight stereotypes by talking about their lives on Twitter, Mirror, 3 April. Available at:

http://www.mirror.co.uk/news/world-news/faces-prostitution-sex-workersfight-5455926 (accessed 28 December 2017)

Bonilla Y and Rosa J (2015) \#Ferguson: Digital protest, hashtag ethnography, and the racial politics of social media in the United States. American Ethnologist, 42(1): 4-17.

Braidotti R (1989) The politics of ontological difference. In Teresa Brennan (ed.), Between Feminism and Psychoanalysis. Routledge. pp. 89-105.

Braidotti R (1993) Embodiment, Sexual Difference, and the Nomadic Subject. Hypatia 8(1): 1-13.

Braidotti, R (2002) Metamorphoses: Towards a Feminist Theory of Becoming. Cambridge: Polity Press.

Bruns A and Burgess JE (2011) The use of Twitter hashtags in the formation of ad hoc publics. In: Proceedings of the 6th European Consortium for Political Research (ECPR) General Conference 2011, University of Iceland, Reykjavik.

Castells M (2012). Networks of outrage and hope - social movements in the Internet age. Chichester, UK: Wiley. 
Chapkis W (1997) Live Sex Acts: Women Performing Erotic Labor. New York: Routledge.

Chatterjee BB (2002) Razorgirls and Cyberdykes: Tracing Cyberfeminism and Thoughts on Its Use in a Legal Context. International Journal of Sexuality and Gender Studies, 7(2-3): 197-213.

Cheng S (2013) Private Lives of Public Women: Photos of Sex Workers (Minus the Sex) in South Korea, Sexualities. 16(1-2): 30-42.

Daniels J (2009) Rethinking cyberfeminism(s): Race, Gender and Embodiment, WSQ: Women's Studies Quarterly, 37(1-2): 101-124.

David G and Cambre C (2016) Screened Intimacies: Tinder and the Swipe Logic, Social Media and Society, 1-11 (April-June).

Ditmore MH, Levy A and Willman A (eds) (2013) Sex Work Matters: Exploring Money, Power and Intimacy in the Sex Industry, London: Zed Books.

Dobson AS (2015) Postfeminist Digital Cultures: Femininity, Social Media, and Self-Representation, New York: Palgrave Macmillan.

Earl J and Kimport K (2011) Digitally Enabled Social Change: Activism in the Internet Age, Cambridge, Massachusetts: MIT Press.

Faris DM (2013) Dissent and revolution in a digital age: Social media, blogging and activism in Egypt. London: IB Tauris.

Fawkes J (2005) Sex Working Feminists and the Politics of Exclusion. Social Alternatives 24(2): 22-23.

Feldman V (2014) Sex work politics and the Internet. In: Showden CR and Majic S (eds) Negotiating sex work: unintended consequences of policy and activism, Minneapolis: University of Minnesota Press, pp.243-226.

Fernandez M, Wilding F and Wright MM. (eds) (2003) Domain Errors! Cyberfeminist Practices, New York: Autonomedia Press.

Flanagan M and Booth A (2002) Reload: Rethinking Women + Cyberculture, Cambridge Massachusetts: MIT Press.

Fotopoulou A (2017) Feminist Activism and Digital Networks: Between Empowerment and Vulnerability. London, UK: Palgrave Macmillan.

Garofalo G (2013) Sex Workers' Rights Activism in Europe: Orientations from Brussels. In: Ditmore MH, Levy A and Willman A (eds), Sex Work Matters: Exploring Money, Power and intimacy in the Sex Industry, London: Zed Books. pp.101-114. 
Gibbs M, Meese J, Arnold M, Nansen B and Carter M (2015) \#Funeral and Instagram: death, social media, and platform vernacular, Information, Communication and Society 18(3): 255-68.

Grosz E (1994) Volatile Bodies: Toward a Corporeal Feminism. Australia: Allen \& Unwin.

Hansen M (2006) Bodies in Code: Interfaces with Digital Media. New York: Routledge.

Haraway D (1990) A Cyborg Manifesto: Science, Technology, and Socialist Feminism in the late Twentieth Century. Minnesota: University of Minnesota Press.

Hayles K (1999) How we became Posthuman: Virtual bodies in cybernetics, literature and informatics, Chicago and London: The University of Chicago Press.

Heim M (1992) The Erotic Ontology of Cyberspace. In: Benedikt M (ed) Cyberspace: First Steps Cambridge, MA: MIT Press. pp.59-80.

Holsti O (1969) Content analysis for the Social Sciences and Humanities, Reading, MA: Addison-Wesley.

Internet Live Stats. Available at: http://www.internetlivestats.com/twitterstatistics/ (Accessed 13 July 2018).

Jerslev A and Mortensen M (2016) What is the self in the celebrity selfie? Celebrification, phatic communication and performativity, Celebrity Studies, 7(2): 249-263.

Jones A (2015) Sex work in a digital era. Sociology Compass 9 7): 558-570.

Juris, JS (2008) Networking Futures: The Movements Against Corporate Globalization, Durham and London: Duke University Press.

Klein, R (1999) If I'm a Cyborg rather than a Goddess will Patriarchy go away? In: Hawthorne S and Klein R (eds) Cyberfeminism: Connectivity, Critique and Creativity. Victoria, Australia: Spinifex Press, pp.185-212.

Kuntsman A (2017) Introduction: Whose selfie citizenship? In: Kuntsman A (ed) Selfie Citizenship. Manchester, UK: Palgrave Macmillan. pp.13-20.

Kurzweil R (1999) The Age of Spiritual Machines: When computers exceed human intelligence. Sydney: Allen \& Unwin.

Laing M, Pilcher K and Smith N (2015) Queer Sex Work, London: Routledge.

Lane F (2000) Obscene Profits: The Entrepreneurs of Pornography in the Cyber Age, New York: Routledge. 
Lanier J and Biocca F (1992) An Insider's View of the Future of Virtual Reality, Journal of Communication, 42(4): 150-172.

Leaver T and Highfield T (2015) Imagining the ends of identity: Birth and Death on Instagram, Selected Papers of Internet Research 16: The 16th Annual Meeting of the Association of Internet Researchers Phoenix, AZ, USA / 21-24 October.

Marwick AE (2015) Instafame: Luxury Selfies in the Attention Economy, Public Culture, 27(1): 137-160.

Mazza F, Da Silva MP and Le Callet P (2014) Would you hire me? Selfie portrait images perception in a recruitment context. Proceedings SPIE 9014, Human Vision and Electronic Imaging XIX, 90140X (25 February).

Moravec H (1988) Mind Children: The Future of Robot and Human Intelligence, Cambridge, Massachusetts: Harvard University Press.

Neuendorf K (2017) The Content Analysis Guidebook. 2nd edtn. London: Sage Publications.

Nouraie-Simone F (2005) Wings of Freedom: Iranian Women, Identity, and Cyberspace. In: Nouraie-Simone F (ed) On Shifting Ground, New York: The Feminist Press.

Parkins W (2000) 'Protesting like a Girl': Embodiment, Dissent and Feminist Agency Feminist Theory 1(1): 59-78.

Pretty Woman (1990) Film (dir. G Marshall). USA: Touchstone Pictures.

Rheingold H (1993) Virtual Communities: Homesteading on the Electronic Frontier Reading, Massachusetts: Addison-Wesley.

Riffe D, Lacy S, \& Fico FG (2005). LEA's communication series. Analyzing media messages: Using quantitative content analysis in research, 2nd edtn. Mahwah, NJ, US: Lawrence Erlbaum Associates Publishers.

Rossiter N (2006) Organized networks: media theory, creative labour, new institutions, NAi, Rotterdam, The Netherlands: Institute of Network Cultures.

Sanders T, O'Neill M and Pitcher J (2009) Prostitution: Sex Work, Policy and Politics London: Sage Publications.

Sanders T, Scoular J, Campbell R, Pitcher J and Cunningham S (2018) Internet Sex Work: Beyond the Gaze. Cham, Switzerland: Springer International Publishing.

Senft T and Baym N (2015) What does the selfie say? Investigating a global phenomenon, International Journal of Communication, 9: 1588-1606. 
Shade LR (1996) Gender issues in computer networks. Paper presented at Community Networking: The international Free-Net Conference, Carleton University, Ottawa, Canada. Available at:

http://www.chebucto.ns.ca/Chebucto/freenets/ottawaconference/papers/leslie regan shade.txt

(accessed 31 December 2017)

Sharp K and Earle S (2003) Cyberpunters and cyberwhores: Prostitution on the Internet. In: Jewkes Y (ed) Dot.cons: Crime, Deviance and Identity on the Internet Cullompton, UK: Willan, pp.36-52.

Sheehan C (2015) The selfie protest: a visual analysis of activism in the digital age. MSc Dissertation, London School of Economics, UK.

Sultana H (2015) Sex worker activism, feminist discourse and HIV in Bangladesh, Culture, Health \& Sexuality 17(6): 777-788.

Sullivan R (2015) Australian sex workers fight back against industry stigma, news.com.au. 31 March. Available at:

http://www.news.com.au/lifestyle/real-life/true-stories/australian-sex-

workers-fight-back-against-industry-stigma/news-

story/e0f2aabf1e261a074d1668afb0ae2fe9 (accessed 28 December 2017)

Sundén J (2003) Material Virtualities: Approaching Online Textual Embodiment, New York: Peter Lang Publishing.

Sutton B (2010) Bodies in Crisis: Culture, Violence and Women's Resistance in Neoliberal Argentina, New Brunswick, NJ: Rutgers University Press.

Tembeck T (2016) Selfies of Ill Health: Online Autopathographic Photography and the Dramaturgy of the Everyday, Social Media and Society (January - March 2016): 1-11.

Thukral J, Ditmore M and Murphy A (2005) Behind Closed Doors: An Analysis of Indoor Sex Work in New York City New York: Urban Justice Center. Available at: http://sexworkersproject.org/publications/reports/behind-closed-doors/ (accessed 31 December 2017)

Tiidenberg K and Cruz EG (2015) Selfies, Image and the Re-making of the Body, Body \& Society, 21(4): 77-102.

Tiidenberg K (2014) Bringing sexy back: Reclaiming the body aesthetic via selfshooting. Cyberpsychology: journal of Psychosocial Research on Cyberspace, 8(1). Available at: https://cyberpsychology.eu/article/view/4295/3342 (Accessed 21 July 2018)

Tiidenberg K (2013) How does online experience inform our sense of self? NSFW bloggers' identity narratives. In: Allaste AA (ed.) Changes and Continuities of Lifestyles in Transforming Societies. Frankfurt am Main: Peter Lang, pp.177-202. 
Travers A (2003) 'Parallel subaltern feminist counterpublics in cyberspace', Sociological Perspectives, 46(2): 223-237.

Turkle S (1995) Life on the Screen: Identity in the Age of the Internet. New York: Simon and Schuster.

van der Nagel E (2013) Faceless Bodies: Negotiating Technological and Cultural Codes on reddit gonewild, Scan: Journal of Media, Arts, Culture, 10(2). Available at: https://researchbank.swinburne.edu.au/file/74ca6308-49b3-42fe-ad4ff1cbe8cbb05f/1/PDF\%20\%28Published\%20version\%29.pdf (accessed 21 July 2018) 